\title{
Flow-volume loops derived from three-dimensional echocardiography: a novel approach to the assessment of left ventricular hemodynamics Kambiz Shahgaldi*1, Emil Söderqvist ${ }^{2}$, Petri Gudmundsson ${ }^{3}$, Reidar Winter ${ }^{1,4}$, Jacek Nowak ${ }^{4}$ and Lars-Åke Brodin ${ }^{5}$
}

Address: ${ }^{1}$ Department of Cardiology, Karolinska University Hospital Huddinge, Stockholm, Sweden, ${ }^{2}$ St. Jude Medical, Järfälla, Sweden, ${ }^{3}$ Health Care Group, Malmö, Sweden, ${ }^{4}$ Department of Clinical Physiology, Karolinska University Hospital Huddinge, Stockholm, Sweden and ${ }^{5}$ School of Technology and Health, Royal Institute of Technology, Flemingsberg, Stockholm, Sweden

Email: Kambiz Shahgaldi* - kambiz.shahgaldi@karolinska.se; Emil Söderqvist - esoderqvist@sjm.com; Petri Gudmundsson - pg@hhgab.com; Reidar Winter - reidar.winter@karolinska.se; Jacek Nowak - jacek.nowak@ki.se; Lars-Åke Brodin - lars-ake.brodin@syd.kth.se

* Corresponding author

Published: 4 April 2008

Cardiovascular Ultrasound 2008, 6:13 doi:10.1186/1476-7/20-6-13
Received: 13 February 2008

Accepted: 4 April 2008

This article is available from: http://www.cardiovascularultrasound.com/content/6/I/13

(c) 2008 Shahgaldi et al; licensee BioMed Central Ltd.

This is an Open Access article distributed under the terms of the Creative Commons Attribution License (http://creativecommons.org/licenses/by/2.0), which permits unrestricted use, distribution, and reproduction in any medium, provided the original work is properly cited.

\begin{abstract}
Background: This study explores the feasibility of non-invasive evaluation of left ventricular (LV) flow-volume dynamics using 3-dimensional (3D) echocardiography, and the capacity of such an approach to identify altered LV hemodynamic states caused by valvular abnormalities.

Methods: Thirty-one patients with moderate-severe aortic (AS) and mitral (MS) stenoses (2I and 10 patients, respectively) and 10 healthy volunteers underwent 3D echocardiography with full volume acquisition using Philips Sonos 7500 equipment. The digital 3D data were post- processed using TomTec software. LV flow-volume loops were subsequently constructed for each subject by plotting instantaneous LV volume data sampled throughout the cardiac cycle vs. their first derivative representing LV flow. After correction for body surface area, an average flow-volume loop was calculated for each subject group.

Results: Flow-volume loops were obtainable in all subjects, except 3 patients with AS. The flowvolume diagrams displayed clear differences in the form and position of the loops between normal individuals and the respective patient groups. In patients with AS, an "obstructive" pattern was observed, with lower flow values during early systole and larger end-systolic volume. On the other hand, patients with MS displayed a "restrictive" flow-volume pattern, with reduced diastolic filling and smaller end-diastolic volume.

Conclusion: Non-invasive evaluation of LV flow-volume dynamics using 3D-echocardiographic data is technically possible and the approach has a capacity to identify certain specific types of alteration of LV flow-volume pattern caused by valvular abnormalities, thus reflecting underlying hemodynamic states specific for these abnormalities.
\end{abstract}

\section{Background}

Measurement of left ventricular end-systolic (ES) as well as end-diastolic (ED) volumes and LV ejection fraction $(\mathrm{EF})$ is a well-established procedure in the evaluation of 
cardiac function. Two-dimensional (2D) echocardiography is the most commonly used imaging modality in the diagnosis of heart diseases and the primary tool for the assessment of LV function and volumes. However, 2D echocardiography has limited reproducibility due to the fact that algorithms for the calculation of LV volumes and $\mathrm{EF}$ are based on certain geometrical assumptions that do no necessarily hold true in different clinical scenarios, as for example, in the presence of regional wall motion or structural abnormalities and dilated ventricles with changed geometry [1-3]. Nevertheless, 2D-echocardiography-based assessment of EF and LV volumes still not only provides important diagnostic information, but can also be used as a therapeutic guidance and prognostic instrument $[4,5]$.

Three-dimensional echocardiography offers the possibility of a more accurate assessment of LV volumes and EF. Studies performed hitherto have consistently demonstrated improved accuracy of LV volumetry by $3 \mathrm{D}$ echocardiography [6-13] compared to $2 \mathrm{D}$ technique $[7,14,15]$. One of the disadvantages of the 3D-echocardiographic approach is the fact that it is rather time consuming due to the necessity of manual tracing of endocardial borders in several LV slices [11]. However, the newly introduced real-time 3D technique with semi-automated border tracing allows faster acquisition of 3D data sets with good image quality and faster data analysis. Nevertheless, the assessment of LV function from end-systolic and end-diastolic $L V$ volumes remains in its essence rather crude and does not provide any detailed hemodynamic data from the LV filling and ejection phases.

The most reliable method for the evaluation of LV contractility is the simultaneous, real-time measurement of LV pressure and volume and the analysis of thus created pressure-volume loop diagram [16]. However, the procedure has a disadvantage of being invasive and is therefore seldom used in clinical practice. An alternative, non-invasive way to the assessment of LV contractility has been proposed and involves analysis of the relationship between sphygmomanometrically measured systolic blood pressure (substitute of LV end-systolic pressure) and echocardiographically derived LV end-systolic volume at rest and during exercise [17]. Recently, Söderqvist et al. described a new non-invasive approach to the assessment of LV function based on the analysis of LV flow-volume relationship in time domain using estimates of LV volume and flow derived from echocardiograpic variables [18]. The concept of cardiac flow-volume measurements originates from the flow-volume analysis that has been for long generally applied as a clinical measure of lung function and differentiation between obstructive and restrictive disorder. Similarly, the LV flow-volume relationship throughout the cardiac cycle presented as a flow-volume loop can be expected to show different characteristic pattern in different specific hemodynamic situations and to provide thereby useful diagnostic information and therapeutic guidance.

Three-dimensional echocardiography provides possibility of a direct measurement of LV volumes and the first derivative of LV volume would describe blood flow in and out of the LV. Hence, by using volume and flow data extracted from the 3-D data set acquired throughout the cardiac cycle, left ventricular flow-volume loops can be constructed. The aim of the present study was to explore the feasibility of non-invasive evaluation of LV flow-volume dynamics using 3D echocardiography, and to assess the diagnostic potential of such flow-volume loops in two different types of hemodynamic pathologies, i.e. the obstructive disorder due to aortic stenosis and the restrictive state resulting from mitral stenosis.

\section{Methods}

The study population consisted of 41 subjects. Thirty-one of them ( 17 women and 14 men, aged $72 \pm 12$ years) were patients referred to the Department of Cardiology, Malmö University Hospital for echocardiographic evaluation of mitral or aortic stenosis, and 10 subjects ( 3 women and 7 men, aged $32 \pm 3$ years) were healthy volunteers. In addition to standard 2D echocardiography, 3D echocardiography was performed in all subjects. The severity of the mitral and aortic stenosis was defined according to the clinical practise guidelines at Malmö University Hospital and in agreement with ACC/AHA guidelines [19] as mild, moderate, moderate-severe, or severe. The assessment of the severity of the valvular stenoses was performed using a combination of qualitative and quantitative analysis based on echocardiographic spectral and colour Doppler measurements. The study was approved by the Ethics Committee of the Lund University Hospital and all study subjects gave their informed consent to participate.

\section{D echocardiography}

All 3-D echocardiographic examinations were performed by the same experienced sonographer with the patient in the left lateral position. 3D images were acquired over 4 consecutive cardiac cycles during a breath hold from the apical window using Sonos 7500 equipment and a full matrix array ultrasonographic (x4) transducer (Philips, Andover, Mass., U.S.A.). The sampling frequency of 3D data was $15-24$ frames/s. The acquired data sets were stored on CD-ROM disks and transferred to a standard PC for subsequent off-line analysis using commercially available software 4D LV-Analysis CRT 1.0 (TomTec, Unterschlessheim, Germany). The analysis started with the definition of long axis plane in apical 5-chamber view, whereupon 6 long axis image planes of LV were automatically generated. In each of the 6 image planes, the posi- 
tion of mitral valve, aortic valve and apex was marked at the end of systole (smallest LV cavity size) and diastole (largest LV cavity size). The semi-automated border detection algorithm provided subsequently a delineation of LV endocardial border with a preconfigured ellipse that was manually adjusted and the total endocardial border in all frames could be defined. The analysis program allowed then a reconstruction of $L V$ volumes as a dynamic surfacerendered image in which LV wall motion was shown three-dimensionally. A graph describing LV volume changes throughout the cardiac cycle was also obtained (Fig. 1). Left ventricular end-diastolic (LVEDV) and endsystolic (LVESV) volumes as well as LV ejection fraction (LVEF) were automatically provided by the software from the acquired 3D data.

\section{Construction of LV flow-volumes loops}

Using 3D-data set, LV volumes were determined for each frame throughout the cardiac cycle and their respective first derivatives were calculated using Matlab software (version 6.5, TheMathWorks Inc. Natick, MA, U.S.A.). All volume variables were then adjusted for body surface area and plotted against its first derivative (describing LV flow) for each cardiac cycle to create LV flow-volume loops. Subsequently, an average flow-volume loop for each examined patient group was constructed. The created flowvolumes loops are limited to one cardiac cycle and lack time scale having LV volume as $x$-axis. Consequently, expressions pointing to diastolic/systolic early/late flows mean flows at the respective small/large left ventricular volumes.

\section{Statistics}

All values are presented as mean \pm SD. The Student's $t$-test for unpaired samples was used as appropriate.

\section{Results}

3D-echocardiographic data were acquired from all 41 subjects. However, in 3 patients with aortic stenosis (AS), the image quality was poor and their $3 \mathrm{D}$ data have been excluded from analysis.

The clinical characteristics of the study population are presented in Table 1. Significant AS or mitral valvular stenosis (MS) was found in $74 \%$ of the patients, whereas in the resting $26 \%$ of the subjects no cardiac pathology was found. The distribution of the valvular diseases, 3Dechocardiographic volumes, as well as blood pressure and heart rate data in the study population is presented in Table 2. As could be expected, the patients with MS showed smaller LVEDV than the subjects without any valvular pathology ( $\mathrm{p}<0.05)$, and also LVEF was smaller both in the patients with AS and MS, as compared to nonaffected individuals $(\mathrm{p}<0.05)$. Also, the patients with MS had higher heart rate than those with AS $(\mathrm{p}<0.05)$ and the subjects without any valvular disease $(\mathrm{p}<0.001)$.

A schematic diagram of a LV flow-volume loop during one cardiac cycle is presented in Fig. 2. The loop proceeds in clockwise direction with decreasing volume during $\mathrm{LV}$ ejection and increasing LV volumes during diastolic filling. The positive flow values indicate flow into the left ventricle during diastole and the negative values flow out of the left ventricle during systolic ejection. The curve indicates maximal LV volume at the end of diastole and minimal LV volume at the end of systole, and the diastolic Eand A-wave can also be discerned.

The average LV flow-volume loops in patients with severe valvular abnormalities and in individuals without valvular pathology are presented in Fig. 3. As can be seen from the figure, the flow-volume relationships were altered in both left-sided cardiac valvular abnormalities and differed from the typical loop in subjects with unaffected valves. In addition, flow-volume pattern differed between the two studied left-sided valvular pathologies as well. The patients with AS displayed easily discernible slower systolic volume decrease and lower ejection fraction despite maintained LVED volume, thus reflecting hampered systolic ejection. On the other hand, in the patients with MS, the flow-volume loop indicated smaller LVED volumes and smaller ejection fraction implying reduced diastolic LV filling (Fig. 3 and Table 2).

\section{Discussion}

Analysis of invasively derived LV pressure-volume loops is a very useful and reliable method for monitoring of myocardial contractility (16) and an appreciated research tool whenever detailed information about the dynamics of $\mathrm{LV}$ performance is needed. However, the method suffers from its invasiveness that limits its general applicability in clinical cardiology. Therefore, there has been a long-felt need of most cardiologists for an alternative, non-invasive approach to the evaluation of myocardial contractility and it has been proposed that non-invasive measurement of changes in end-systolic pressure/volume ratio (systolic pressure by cuff sphygmanometer/end-diastolic volume by biplane Simpson's rule method) from rest to peak exercise could be used as a sensitive indicator of left ventricular function [20]. Based on this concept, a new noninvasive echocardiographic method has been developed that allows assessment of LV function by analysis of the dynamics of the systolic pressure/end-diastolic volume relationship during physical stress [21], pacing [22], or pharmacological stress with dobutamine [23]. The concept of LV flow-volume loop presented in the present study creates basis for yet another new, non-invasive approach to the assessment of LV function by focussing on a continuous quantitative evaluation of flow-volume 


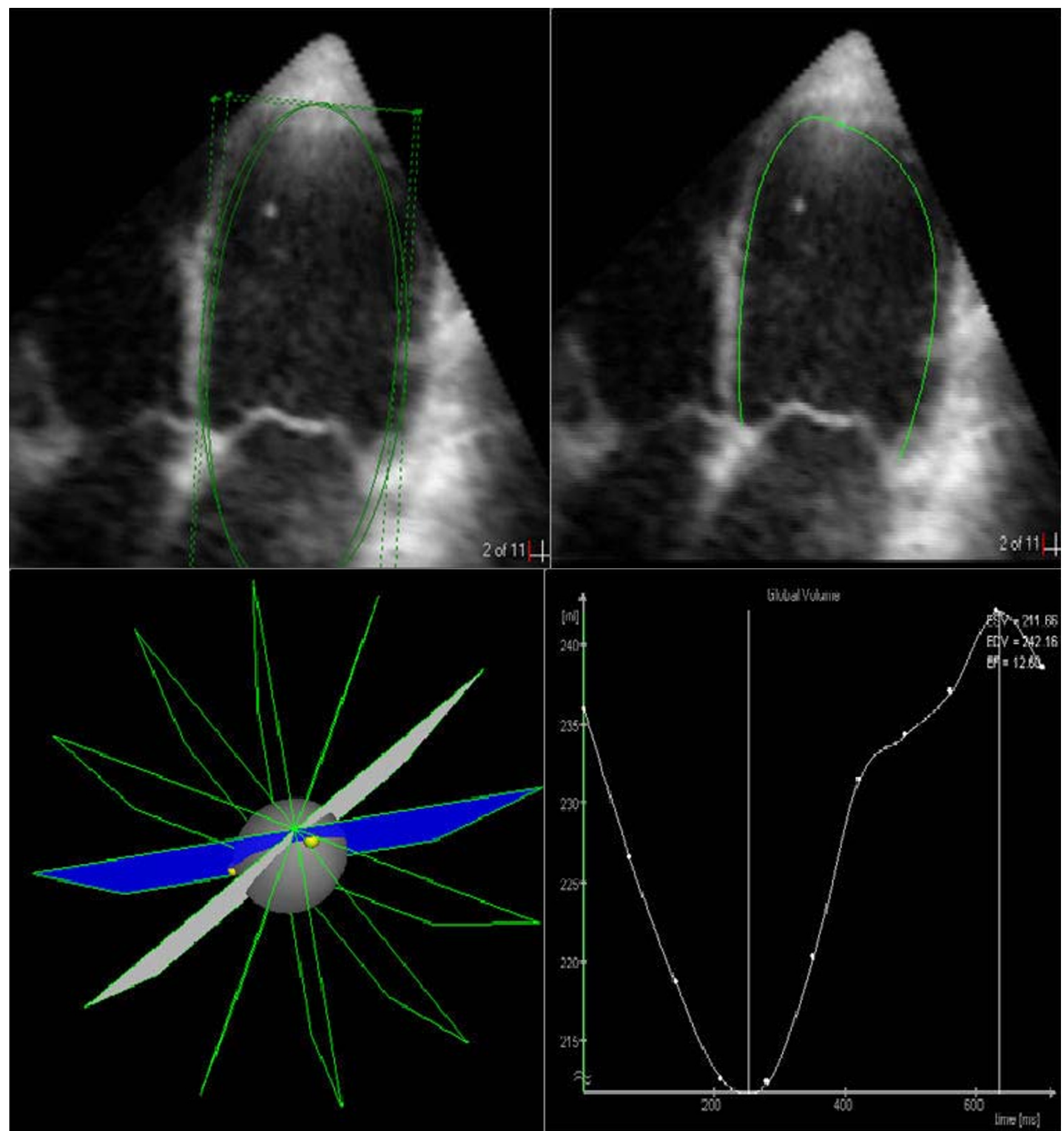

\section{Figure I}

Analysis of LV volumes using 3D-echocardiography. In the selected LV image (upper left), the algorithm (4D LV-Analysis CRT I.0, TomTec) provides semi-automated delineation of the endocardial border (upper right). By superposition of LV contours from 6 insonation planes (lower left) in 3D space, the LV volumes are calculated and the graphic presentation of LV volume changes in time can be obtained (lower right). 
Table I: Clinical characteristics of the study subjects.

\begin{tabular}{lc}
\hline Sinus rhythm & $71 \%$ \\
Dilatead left ventricle & $13 \%$ \\
Dilated left atrium & $50 \%$ \\
Heart failure & $24 \%$ \\
Previous AMI & $11 \%$ \\
Previous PCI & $3 \%$ \\
Previous CABG & $16 \%$ \\
Diabetes & $5 \%$ \\
Significant valvular disease & $74 \%$ \\
Beta-blocker & $37 \%$ \\
ACE inhibitor & $26 \%$
\end{tabular}

AMI: acute myocardial infarction, $\mathrm{PCl}$ : percutaneous coronary intervention, $C A B G$ : coronary artery bypass grafting, $A C E$ : angiotensin converting enzyme

relationship throughout the entire cardiac cycle. In addition to quantifiable variables such as flow and volume, other characteristics of the flow-volumes loops such as, for example, the course of ventricular filling and ejection, and the overall form of the flow-volume loop may also be evaluated qualitatively.

The concept of LV flow-volume loop provides a new and different from pressure-volume loop approach to the estimation of the dynamics of cardiac performance. The approach was originally proposed by Söderqvist et al. [18] and was based on the use of estimates of LV flow and volume derived from 2D echocardiography images. Even if only estimates of LV volumes were used in the abovementioned study, the obtained results clearly proved the technical feasibility of non-invasive monitoring of LV flow-volume relationship. In contrast to study of Söderqvist et al. [18], the LV volumes the present study was measured directly using 3D echocardiography. The inherent limitations of the 2D volume calculations using Simpson's formula based on certain geometrical assumptions was thus eliminated, and consequently, also the present calculation of the first derivative of LV volume representing time-dependent LV flow was more accurate. Indeed, the 3D-echocardiographic quantification of LV volumes has been shown to be highly reproducible and accurate when compared with 2D echocardiography $[3,7,15,24,25]$, magnetic resonance imaging $[3,7,12,26$ -
28], or single photon emission tomography [27]. Hence, the flow-volume curves based on the 3D-echocardiographic measurements can be expected to provide reliable information about LV flow events and simultaneous changes in ventricular volume, complementing thereby other hemodynamic information that may be needed in specific clinical or research settings.

The hemodynamic information that can be retrieved from flow-volume loops describes the dynamics of flow-volume events. For this reason, the present approach is superior to the standard methods of functional LV assessment that use only end-diastolic and end-systolic volumes for calculation of LV ejection fraction. Incorporation of the dynamics of LV flow and volume in the same loop provides a possibility of a new and more detailed assessment of cardiac hemodynamics from different point of view. The continuous information about LV flow and volume expressed by flow-volume loop provides the prerequisites for hemodynamic pattern recognition in health and disease. In this process, the qualitative assessment of flowvolume loop form can be used as a tool for a rapid evaluation of cardiac hemodynamics and differentiation between normal state and different cardiac pathologies, as for example, significant valvular diseases that would change the normal pattern of LV filling and emptying. In the course of disease in any given patient, the sequential comparison of the respective loop forms and positions in the diagram can be easily performed and may provide valuable additional information and therapeutic guidance.

The present results demonstrate that flow-volume loops based on 3D echocardiography measurements indeed have a potential to separate groups of different hemodynamic states. The characteristics of the average flow-volume loops obtained in normal subjects and in patients with AS an MS differed and were easily distinguishable. The patients with AS demonstrated a typical "obstructive" pattern with lower flow values during early systole and larger end-systolic volume as compared to normal pattern. On the other hand, in the patients with MS a "restrictive" pattern with reduced diastolic filling was observed. The prevailing hemodynamic state may thus be rapidly

Table 2: Distribution of the 3D-echocardiographic data, blood pressure and heart rate in the study population.

\begin{tabular}{|c|c|c|c|c|c|c|c|c|c|c|}
\hline \multirow[t]{2}{*}{ Valvular disease } & \multirow{2}{*}{$\begin{array}{l}\text { Number of } \\
\text { subjects }\end{array}$} & \multicolumn{3}{|c|}{ Severity of valvular disease } & \multirow{2}{*}{$\begin{array}{l}\text { LVEDV } \\
\quad(\mathrm{ml})\end{array}$} & \multirow{2}{*}{$\begin{array}{l}\text { LVESV } \\
\text { (ml) }\end{array}$} & \multirow{2}{*}{$\begin{array}{c}\text { LVEF } \\
(\%)\end{array}$} & \multicolumn{2}{|c|}{$\mathbf{B P}$} & \multirow{2}{*}{$\begin{array}{c}\text { HR } \\
\text { (beats/min) }\end{array}$} \\
\hline & & $M(n)$ & $\mathbf{M}-\mathbf{S}(\mathrm{n})$ & $\mathbf{S}(\mathrm{n})$ & & & & $\begin{array}{l}\text { systolic } \\
(\mathrm{mm} \mathrm{Hg})\end{array}$ & $\begin{array}{c}\text { diastolic } \\
(\mathrm{mm} \mathrm{Hg})\end{array}$ & \\
\hline AS & 18 & 7 & 2 & 9 & $110 \pm 46$ & $63 \pm 38$ & $47 \pm 17^{*}$ & $154 \pm 49$ & $75 \pm 12$ & $74 \pm 14^{*}$ \\
\hline MS & 10 & 7 & I & 2 & $83 \pm 26^{*}$ & $42 \pm 12$ & $48 \pm 13^{*}$ & $139 \pm 22$ & $78 \pm 17$ & $88 \pm 13$ \\
\hline None & 10 & 0 & 0 & 0 & $110 \pm 20$ & $46 \pm 10$ & $59 \pm 4$ & $124 \pm 15$ & $72 \pm 9$ & $66 \pm 5 * * *$ \\
\hline
\end{tabular}

M: moderate, M-S: moderate to severe, S: severe, BP: blood pressure, HR: heart rate, ${ }^{*} \mathrm{P}<0.05$ vs. LVEDV/LVEF - no valvular disease, and heart rate $-M S ; * * *<0.001$ vs. Heart $-M S$ 


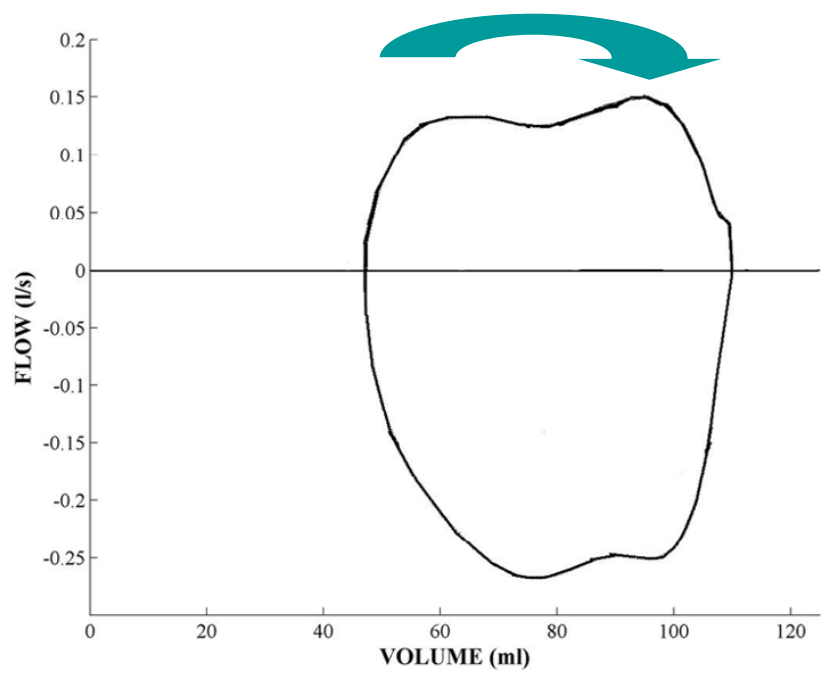

Figure 2

A schematic illustration of flow-volume loop during one cardiac cycle. The loop proceeds in clockwise direction. The upper part of the loop (above zero flow) describes flow-volume relationship during diastole, and the lower part of the loop (below zero flow) shows the relationship during systole.

determined by recognition of a specific typical pattern of flow-volume relationship.

The present methodological approach has, however, some limitations. The major limitation is caused by the

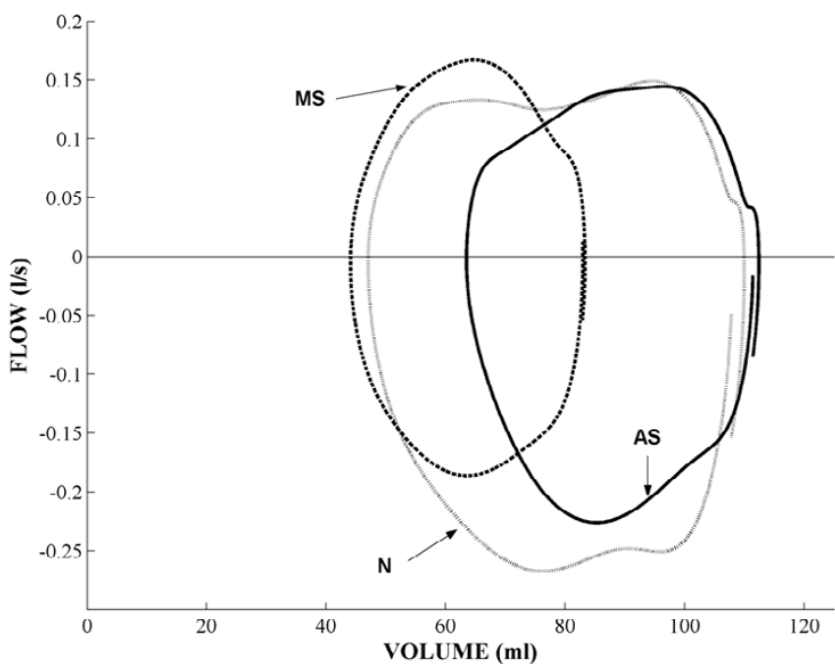

Figure 3

Average LV flow-volume loops in normal individuals (N), and patients with valvular abnormalities (MS and AS). Note the characteristic alteration of the loop form and the position of the loop in the flow-volume diagram in the two patient groups, as compared to healthy subjects. relatively low $3 \mathrm{D}$-echocardiographic sampling rate ranging from 15 to $24 \mathrm{~Hz}$. This would increase the variability of the flow-volume loops. As a consequence, although providing a typical pattern for a group of patients with a specific cardiac pathology, the loops may not yet be applicable on the individual basis. The other important limitation lies in the fact that the same data set is used for calculation of both volume and flow, the latter being calculated as the first derivative of volume. This limitation can be overcome by using integrated 3D colour Doppler in the LV outflow tract for flow measurements and 3D grey scale data for continuous measurement of LV volume. Finally, the image quality is also a limiting factor.

\section{Conclusion}

3D echocardiography offers the possibility of non-invasive estimation of the dynamics of LV flow-volume relationship during cardiac cycle. The approach provides new information about LV hemodynamics and function, and has a capacity to differentiate between normal LV hemodynamics and specific types of alterations of flow-volume relationships caused by valvular abnormalities, such as aortic and mitral stenoses. The method has a potential to provide additional hemodynamic information in the evaluation of cardiac and valvular function.

\section{Competing interests}

The author(s) declare that they have no competing interests.

\section{Authors' contributions}

RW and LÅB initiated the study. RW supervised the study and participated in the interpretation of the results and manuscript preparation. KS performed measurements, made all data conversions, plots and calculations from ultrasound data, and participated in the preparation of the manuscript. PG participated in data collection and interpretation of the results. ES participated in data conversion, creation of plots and calculations from ultrasound data. JN performed statistical analysis and was responsible for final manuscript. All authors read and approved the final manuscript.

\section{References}

I. Gopal AS, Shen Z, Sapin PM, Keller AM, Schnellbaecher MJ, Leibowitz DW, Akinboboye OO, Rodney RA, Blood DK, King DL: Assessment of cardiac function by three-dimensional echocardiography compared with conventional noninvasive methods. Circulation 1995, 92:842-853.

2. Mondelli JA, Di Luzio S, Nagaraj A, Kane RJ, Smulevitz B, Nagaraj AV, Greene R, McPherson DD, Rigolin VH: The validation of volumetric real-time 3-dimensional echocardiography for the determination of left ventricular function. J Am Soc echocardiogr 200I, 14:994-1000.

3. Hibberd MG, Chuang ML, Beaudin RA, Riley MF, Mooney MG, Fearnside JT, Manning WJ, Douglas PS: Accuracy of three-dimensional echocardiography with unrestricted selection of imaging planes for measurement of left ventricular volumes and ejection fraction. Am Heart J 2000, I40:469-475. 
4. Pfeffer MA, Braunwald E, Moye LA, Basta L, Brown EJ Jr, Cuddy TE, Davis BR, geltman EM, Goldman S, Flaker GC: Effect of captopril on mortality and morbidity in patients with left ventricular dysfunction after myocardial infarction: results of the survival and ventricular enlargement trial. $N$ Engl J Med 327:669-677.

5. The Acute Infarction Ramipril efficacy (AIRE) Investigators: Effect of ramipril on mortality and morbidity of survivors of acute myocardial infarction with evidence of heart failure. Lancet 1993, 342:821-827.

6. Houck Robin C, Cooke Jason E, Gill Edward A: Live 3D echocardiography: A replacement for traditional 2D echocardiography. AJR 2006, 187:1092-1106.

7. Gopal A, Keller AM, Rigling R, King DL Jr, King DL: Left ventricular volume and endocardial surface area by three-dimensional echocardiography: Comparison with two-dimensional echocardiography and nuclear magnetic resonance imaging in normal subjects. I Am Coll Cardiol 1993, 22:258-270.

8. Chuang Michael L, Hibberd Mark G, Salton Carol J, Beaudin Raymond A, Riley Marilyn F, Parker Robert A, Douglas Pamela S: Importance of imaging method over imaging modality in noninvasive determination of left ventricular volumes and ejection fraction. JACC 2000, 35:477-484.

9. Kotaro A, Takeshi H, Yoshiki M, Kenichi S, Yusuhiko T, Hiroyuki Y, Minoru Y, Hiroshi K, Junichi Y: Accuracy of measurement of left ventricular volume and ejection fraction by new real-time three-dimensional echocardiography in patients with wall motion abnormalities secondary to myocardial infarction. J Am Cardiol 2004, 94:552-558.

10. Jenkins C, Bricknell K, Hanekom L, Thomas Marwick H: Reproducibility and accuracy of echocardiographic measurements of left ventricular parameters using real-time three-dimensional echocardiography. JACC 2004, 44:878-886.

II. Nixdorff U, Feddesen I, Voigt J-U, Flachskampf F-A: Three-dimensional echocardiography. Rational mode of component images for left ventricular volume quantitation. Cardiology 2005, 104:76-82.

12. Mannaerts HF, Van Der Heide JA, Kamp O, Papavassiliu T, Marcus JT, Beek A, Van Rossum AC, Twisk J, Visser CA: Quantification of left ventricular volumes and ejection fraction using free hand transthoracic three-dimensional echocardiography: comparison with magnetic resonance imaging. I Am Soc Echocardiogr 2003, 16:101-109.

13. Pearlman AS: Measurement of left ventricular volume by three-dimensional echocardiography present promise and potential problems. J Am Coll Cardiol 1993, 22:1538-1540.

14. Gopal A, King D, Keller A, rigling R: Superiority of three-dimensional echocardiography in human subjects for ventricular volume computation compared to two-dimensional apical biplane summation of disc method. Circulation 1992, 86:1270-276.

15. Sapin PM, Schröder KD, Smith MD, De Maria AN, King DL: Threedimensional echocardiography measurement of left ventricular volume in vitro: Comparison with two-dimensional echocardiography and cineventriculary. J Am Coll Cardiol 1993, 22:TI530-I537.

16. Suga $\mathrm{H}$ : Left ventricular time-varying pressure/volume ratio in systole as an index of myocardial inotropism. Jpn Heart J 197I, I 2:153-160.

17. Bombardini T: Myocardial contractility in the echolab: molecular, cellular and pathophysiological basis. Cardiovascular Ultrasound 2005, 3:27.

18. Söderqvist E, Cain P, Lind B, Winter R, Nowak J, Brodin L-Å: Feasibility of creating Estimates of left ventricular flow-volume dynamics using echocardiography. Cardiovascular Ultrasound 2006, 4:40.

19. Bonow RO, Carabello BA, Kanu C, de Leon AC Jr, Faxon DP, Freed MD, Gaaschs WH, Lytle BW, Nishimura RA, O'Gara PT, O'Rourke RA, Otto CM, Shah PM, Shanewise JS, Smith SC Jr, Jacobs AK, Adams CD, Anderson JL, Antman EM, Faxon DP, Fuster V, Halperin JL, Hiratzka LF, Hunt SA, Lytle BW, Nishimura R, Page RL, Riegel B: ACCIAHA 2006 guidelines for the management of patients with valvular heart disease: a report of the American College of Cardiology/American Heart Association Task Force on Practice Guidelines (writing committee to revise the 1998 Guidelines for the Management of Patients With Valvular
Heart Disease): developed in collaboration with the Society of Cardiovascular Anesthesiologists: endorsed by the Society for Cardiovascular Angiography and Interventions and the Society of Thoracic Surgeons. Circulation I I4(5):e84-23 I. 2006 Aug I

20. Ginzton LE, Laks MM, Brizendine M, Conant R, Mena I: Noninvasive measurement of the rest and exercise peak systolic pressure/end systolic volume ratio: a sensitive indicator of left ventricular function. J Am Coll Cardiol 1984, 4:509-5I6.

21. Bombardini T, Correia MJ, Cicerone, Agricola E, Ripoli A, Picano E: Force-frequency relationship in the echocardiography laboratory: a non-invasive assessment of Bowditch treppe? J Am Soc Echocardiogr 2003, 16:646-655.

22. Bombardini T, Agrusta M, Natsvlishvili N, Solimene F, Pap R, Coltorti F, Varga A, Mottola G, Picano E: Noninvasive assessment of left ventricular contractility by pacemaker stress echocardiography. Eur J Heart Failure 2005, 2: I73-181.

23. Grosu A, Bombardini T, Senni M, Duino V, Gori M, Picano E: Endsystolic pressure/volume relationship during dobutamine stress echo: a prognostically useful non-invasive index of left ventricular contractility. Eur Heart J 2005, 26:2404-24I2.

24. Buck T, Hunold P, Wentz KU, Tkalec W, Nesser HJ, Erbel R: Tomographic three-dimensional echocardiographic determination of chamber size and systolic function in patients with left ventricular aneurysm. Comparison to magnetic resonance imaging, cineventriculography, and two-dimensional echocardiography. Circulation 1997, 96:4286-4297.

25. Gutiérrez-Chico JL, Zamorano JL, Pérez de Isla L, Orejas M, Almeria C, Rodrigo JL, Ferreiros J, Serra V, Macaya C: Comparison of left ventricular volumes and ejection fraction measured by three-dimensional echocardiography versus by two-dimensional echocardiography and cardiac magnetic resonance in patients with various cardiomyopathies. Am J Cardiol 2005, 95:809-8I3.

26. Caiani EG, Corsi C, Zamorano J, Sugeng L, MacEneaney P, Weinert L, Battani R, Gutierrez JL, Koch R, Perez de Isla L, Mor-Avi V, Lang RM: Improved semiautomated quantification of left ventricular volumes and ejection fraction using 3-dimensional echocardiography with full matrix-array transducer: comparison with magnetic resonance imaging. J Am Soc Echocardiogr 2005, I 8:779-788.

27. Chan J, Jenkins C, Khafagi F, Du L, Marwick TH: What is the optimal clinical technique for measurement of left ventricular volume after myocardial infarction? A comparative study of 3-dimensional echocardiography, single photon emission computed tomography, and cardiac magnetic resonance imaging. J Am Soc Echocardiogr 2006, 19:192-201.

28. Krenning B], Voormolen MM, van Geuns R-J, Vletter WB, Lancée CT, de Jong N, Ten Cate FJ, van der Steen AFW, Roelnadt JRTC: Rapid and accurate measurement of left ventricular function with a new second-harmonic fast-rotating transducer and semiautomated border detection. Echocardiography 2006, 23:447-454

Publish with Bio Med Central and every scientist can read your work free of charge

"BioMed Central will be the most significant development for disseminating the results of biomedical research in our lifetime. "

Sir Paul Nurse, Cancer Research UK

Your research papers will be:

- available free of charge to the entire biomedical community

- peer reviewed and published immediately upon acceptance

- cited in PubMed and archived on PubMed Central

- yours - you keep the copyright 